\title{
Dentofacial orthopeadics in pediatric dentistry
}

\author{
Esber Çaglar ${ }^{*}$, Dorian Hysi ${ }^{2}$ and Ozgur Onder Kuscu ${ }^{1}$ \\ ${ }^{1}$ Private Practice, Paediatric Dentistry, Istanbul, Turkey \\ ${ }^{2}$ School of Dentistry, Univeristy of Tirana, Albania
}

\begin{abstract}
Human face is the direct message to anyone (s)he meets for the first time. Genetics and environment effects our face as it is mostly shaped during intrauterine life to adolescence. A pediatric dentist is one of the practioners who meets the wondering child in these referred early ages. Besides genetic backround, deleterious habits such as duration of breastfeeding, bottle feeding, finger sucking or an object should be noted. While examing a child patient, the practioner should interfere with how the child's face look, evaluate the proportions of the face, further check if there are nay malocclusions, take a good anamnesis of nasal and oral habits. The present review emphasis the importance of dentofacial orthopeadic in children.
\end{abstract}

\section{Introduction}

Human face is the direct message to anyone (s)he meets for the first time. This message has many counterparts such as sending images of question, surprise, fun, suspicion, anxiety, warm, beauty, etc. In the last century, media guided societies culturally through facial expressions. Actually these messages are influenced by genetics and environments as face is mostly shaped during intrauterine life to adolescence. Major ratios between face points such as eye, eyebrows, chin, lips, musculature, nose, forehead, hairy shin, ears constitute the early signals of this message. A pediatric dentist is one of the practioners who meets the wondering child in these referred early ages. During this first meeting, a detailed anamneses, extraoral and intraoral examination is regular while it should be also necessary to view parental face types regarding orthodontic and orthopeadic aspects. Besides, detecting dental caries, erosion, trauma and malocclusions; it is important to see dentofacial conditioning concluding to orthodontics. At this point a brief summary of oral habits would guide us to proper diagnosis with the aid of intraoral and extraoral examination. What is the message here?

Besides genetic backround, deleterious habits such as duration of breastfeeding, bottle feeding, finger sucking or an object should be noted. Parents would also guide us regarding breathing from nose or mouth, impaired nasal breathing, otorhinolarengeal health issues, allergies, asthma, upper respiratory system dieseas and atypical swallowing. It must be noted that these clinical parameters are considered to be important factors in the aetiology of malocclusion [1-3]. Sometimes parents inform us regarding child's doctor and medicaments, if (s)he drools on a pillow at night, sucks finger, pacifier or an object, breaths from mouth while sleeping or watching TV. However it should be noted that parents may not observe this pathological condition as they are used it to for a long time. Nor one of the parents is also has the same facial appearence as they feel its something related to proud, luck or feel of being familiar. At this point Proffit et al. [4] states the importance of genetic compound on facial features such as the tilt of the nose, the shape of the jaw, the formation of the lips, and the look of the smile. The authors also added that certain types of malocclusions also run in families. The classic "adenoid facies" characterized by narrow width dimension, protruding teeth and lips seperated at rest, has often been attributed to mouth breathing. Within exceptions of exercise, and physiologic mouth breathing, obstructed nose breathing is hard and this resistance ton asal breathing switches the child to partial mouth breathing. This kind of long duration respiration may guide the child to posture and soft tissue change. Tourne and Schweiger [5] stated that nasal obstruction guides humans to 5 degrees change in craniovertebral angle. By this way jaws move a part, as much by elevation of the maxilla and depression of the mandible [4]. Most of these children has long buccal corridors, short philtrum, and stiff musculature of orbicularis oris. (Figure 1) However in some cases this pathological extraoral view may not guarantee a malocclusion while soft tissue may hide malocclusions in many cases. In a recent clinical study children who were mouth breathers demonstrated considerable backward and downward rotation of the mandible, increased overjet, increase in the mandible plane angle, a higher palatal plane, and narrowing of both upper and lower arches at the level of canines and first molars compared to the nasal breathers group. The prevalence of a posterior cross bite was significantly more frequent in the mouth breathers group than nose breathers Abnormal lip-to-tongue anterior oral seal was significantly more frequent in the mouth breathers group than in the nose breathers group [6]. Vice versa Cazzolla et al. [7] stated that habitual snoring and obstructive sleep apnoea syndrome (OSAS) are significant problems for children and may be associated with diurnal symptoms. The authors also concluded that the presence of malocclusion increases the likelihood of sleep-related breathing disturbances such as obstructive sleep apnoea syndrome. Apnoea is a breathing disorder with the absence of airflow at the nose or mouth where children may present adenotonsillar hypertrophy, neuromuscular disorders and craniofacial anomalies.

*Correspondence to: Esber Caglar, Pentadent, Nemutlu apt 69/4 Acıbadem Cad, Acıbadem, Kadiöy, Istanbul, Turkey, Tel: + 90532 6838600; E-mail : caglares@ yahoo.com

Key words: child, dentofacial orthopeadics, malocclusion, orthodontics, pediatric dentistry, sucking

Received: February 12, 2018; Accepted: February 15, 2018; Published: February 17,2018 


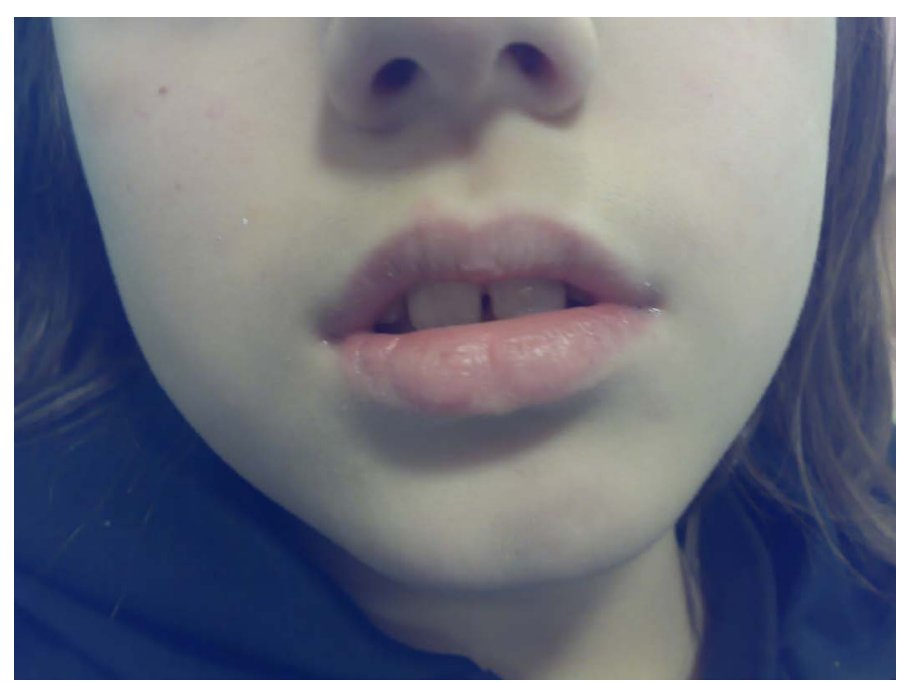

Figure 1. Note the nondisclosure of dried lips

The most common treatment for in childhood is adenotonsillectomy. Therefore, in cases of related dentofacial corrrections, it is also obvious to send the child patient to a otorhinolarengioist for a consultation. However it should be noted that most of these cases would be followed or operated regarding otorhinolarengeal pathologies while the lazziness of these musculature and not having usage of nose guides the face into a very special dentofacial anomaly including a bruise like colour under eyes (Figure 2). A pediatric dentist may detect and note this kind of breathing mode through different ways.

\section{Control of air passage}

Farčnik and Rudel et al. [8], introduced an airflow instrument that registers the difference in airflow temperature through the mouth or nose in subjects with an incompetent lip seal, thus distinguishing mouth breathing from an incompetent lip seal. By this way functional malocclusion traits would be registered during clinical examination and the mode of breathing determined with (Figure 3).

\section{Determination of oral habits}

Human infants characteristically suck in two different ways, depending on whether sucking is nutritive or nonnutritive [9-10]. Non-nutritive sucking is organized as a series of bursts separated by brief pauses [10-12], whereas nutritive sucking is almost continuous and occurs at a slower pace. It has been suggested that nutritive and non-nutritive sucking involves two functionally distinct motor patterns with presumably different central nervous control mechanisms [12].

Larsson et al. [13] suggested an explanation for the significant differences in the prevalence and duration of breast-feeding between today's rearing of babies and the situation among our ancestors. The author stated: "The infant has a sucking instinct that varies in degree among individuals, but is usually powerful. After the child's first cereal or mother's milk, a surplus sucking urge often remains. The extent of this surplus is dependent on the extent of the original urge, on how much of it has been spent on the original urge, and on how much of it has been spent on the intake of nourishment. The surplus sucking urge may be either frustrated or re-channelled. For the child, the most attractive method (and probably the most original) is unrestricted, sometimes non-nutritive sucking. If this possibility is not available, the child must choose between digit and pacifier-sucking to obtain satisfaction. If the surplus sucking urge is not so strong, it can probably be diverted and the child can find satisfaction through physical closeness and cuddling/stimulation." The way babies and young children are reared is important to their health and development. Extensive breast-feeding has also been shown to reduce the development of artificial sucking habits like digit or pacifier-sucking. In a recent study done by Caglar et al. [14], authors pointed out considerable differences in feeding, as well as artificial sucking habits, in Europe, Asia, North and South America at different periods. The prevalence of breast-feeding and bottle-feeding were very high all around the world. Regarding study populations results, except for American children, the prevalence of

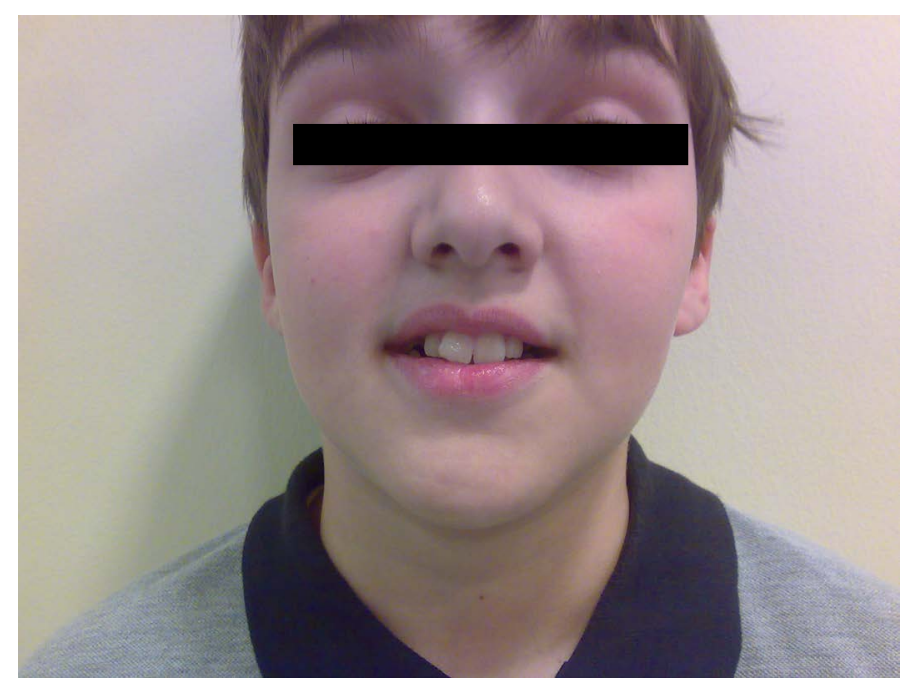

Figure 2. A typical mouth breather, 10 yrs old boy. Note prominent buccal corridors, upheading philtrum, increased lower face height, openmouth and facial assymetry. Patient had been adenoidectomized at age 8

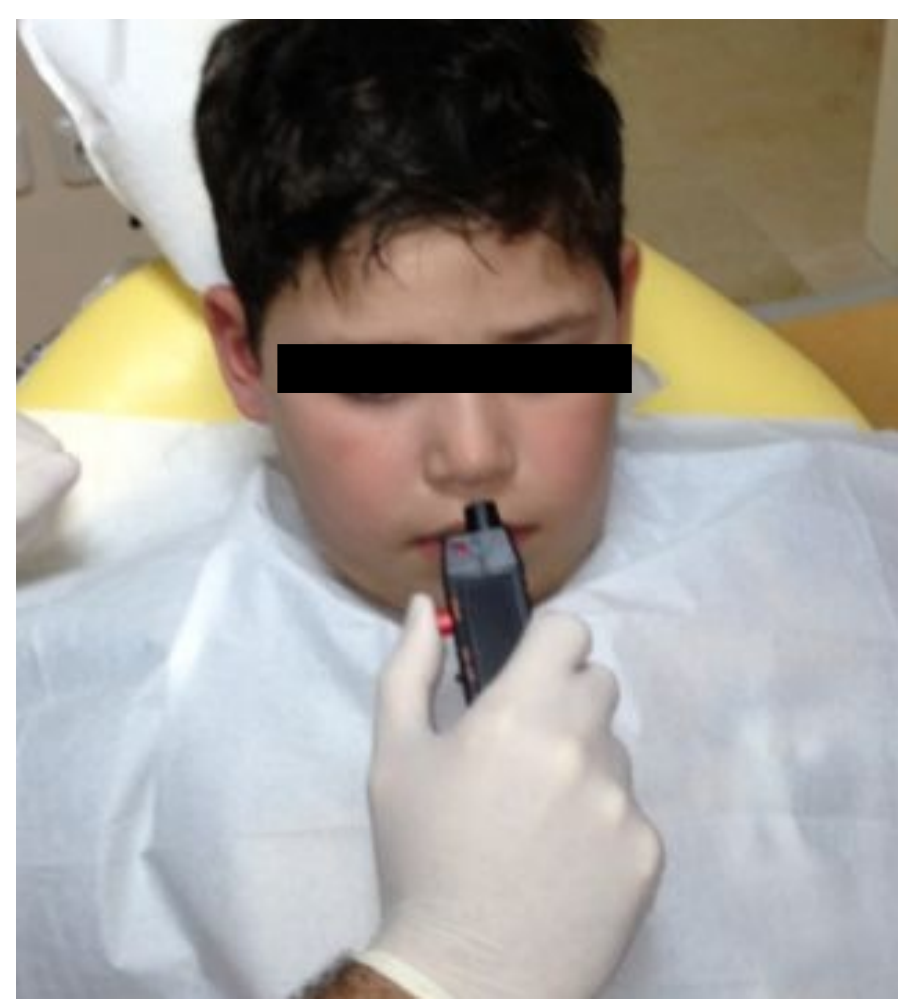

Figure 3. The breathing detector is placed in front of the mouth (distance, $1 \mathrm{~cm}$ ), and the light sign or the beep signal on the airflow registration device confirms airflow through the mouth 
digit-sucking was relatively low. Pacifier-sucking is fairly popular in most areas, with the exception of Japanese children examined.

It should be noted that finger sucking might have been less openly and been difficult to observe (Figure 4). It is because sometimes the attitude of parents to this habit is remarkably negative and should not be stated to somebody else [15].

An understanding of muscular actions during sucking a pacifier or a bottle is necessary for obtaining information on the effectiveness of this particular sucking habit, muscular exercise in the growth and functional development of the stomatognathic system, and possible future implications regarding articulation of speech, swallowing, respiration, and dental occlusion. Continuous pressures of the lips, tongue and muscularis mentalis can alter the normal position of the teeth. This is particularly true, for the forces that act during mastication and speech, as well as the forces exerted by the muscles at rest. However one should note the importance of timing and duration of the habit. Children younger than 5 yrs old and in primary dention produce malocclusions that would be fading away, while children older than 5 yrs old and in mixed dention are prone to more dentofacial problems [15]. Children who engages in nonnutritive sucking habits more than 6 hrs a day, produces significant malocclusions.

It is widely known that there is a relationship between malocclusions and surrounding muscles. It is also questionable sucking, malocclusions, genetics and muscle forces confer each other expressing the result of chicken-egg, egg-chicken.

At this point, evaluation of muscle forces is an important parameter to understand our facial pattern. EMG was a pioneers device used to better understand the physiology of the perioral musculature since 1960s [16-17]. Recently Lindner and Hellsing et al. [18] studied the sucking pattern and intra-oral negative air pressure simultaneously with the cheek/lip pressure in children aged between 6 and 11 years when sucking a pacifier. The authors stated that during pacifier sucking the mean cheek/lip pressure was 3.4 times higher against the canine compared to the second molar. According to authors, the circumoral muscles were especially active during pacifier sucking, in addition to the cheek pressure in the canine region. As the pressures were higher against the canines than the molars, their results help to explain why the primary canines are often the first teeth noted to be in crossbite in children with sucking habits [18]. In another study, the function and the level of activity of the orbicularis oris and of the mentalis muscles were verified by an EMG in resting position and in the movements of sucking a pacifier, and carried out in children aged 8-12 years, divided

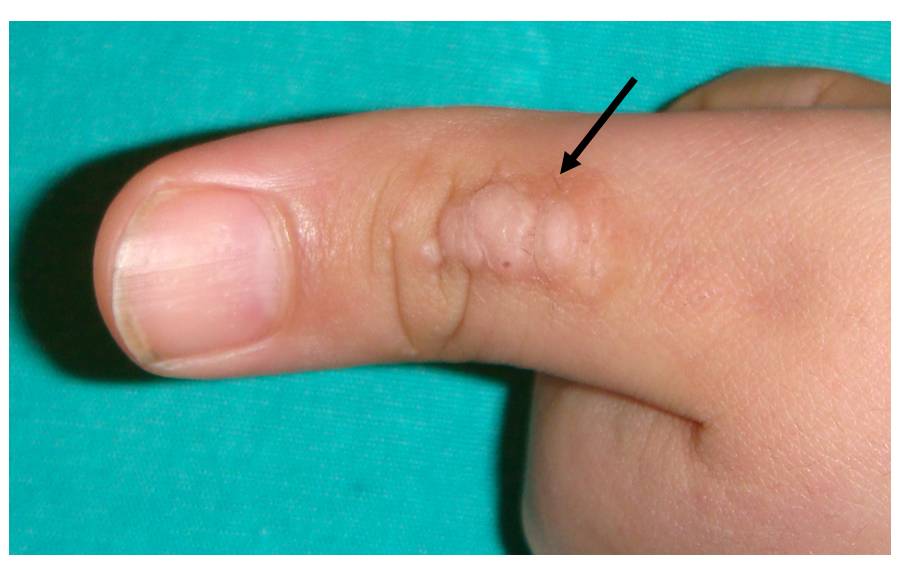

Figure 4. A thumb with keratosis due to prolonged digitsucking into three groups: one with normal occlusion, and two with Class II division I, with atypical swallowing and/or incompetent lips, who had received no orthodontic treatment. All children presented greater activity of the orbicularis oris over the mentalis while sucking a pacifier [19]. Recently, in his clinical study, Ahlgren et al. [20] used EMG to study the facial muscles used in sucking. The results of this EMG study, children who had previously exhibited pacifier sucking clearly showed the strong involvement of the orbicularis oris and mentalis muscles. However it is inaccurate to evaluate the physiology of oral musculature network with EMG solely today.

No doubt an increase in lip and cheek activity occurs, particularly during pacifier sucking, but the constricted maxillary arch may also be explained by the negative pressure created within the mouth, which forces the cheek against the dental arch. These factors along with the low tongue position during sucking alter the soft tissue balance between tongue and cheek pressures against the upper dental arch (Figure 5a,b). A current study demonstrates that in about half of premature babies the mandible does move forward when they are sucking on a pacifier, probably involving perioral musculature [21].

Regarding concerns above design developments in pacifiers included the provision for different shaped teats (nipples) some of which, the so-called "orthodontic" or "anatomical shapes" were claimed to mimic the mother's breast and/or reduce the risk of malocclusions. Perhaps the first description of a so-called "orthodontic" pacifier was by Meach in 1962 [22]. A recommendation was made to avoid causing an anterior open bite, to help maintain adequate maxillary arch width, and to decreases the possibility of causing other oral habits, such as tongue-thrust. Later in 1974, Rutrick et al. [23] gave a slightly more detailed description of the use of a so-called orthodontic pacifier to correct a posterior crossbite in a child who had been using a traditional pacifier. Today there are also remarks to find solutions to develop the best adapted novel dummies which prevents formation of malocclusions or dental caries however evidence based studies are further needed [24,25].

It is important to have a consultation with an orthodontist for the long journey of foreseen orthodontic treatment. However it should be also emphasized that even a successful orthodontic treatment may not solve the problem of mouth breathing and the unwanted facial expression. Therefore our aim of pre-orthodontics is to treat malocclusions while additionally secure the closure of lips, usage of nose breathing way, a normal swallowing pattern and diselimination of delitirious habits. If cause is not foressen like an upperway infection or adenoitis (Figure 6).

Harari et al. [6] determined the effect of mouth breathing during childhood on craniofacial and dentofacial development compared to nasal breathing in malocclusion patients treated in the orthodontic clinic. The authors stated that the naso-respiratory obstruction with mouth breathing during critical growth periods in children has a higher tendency for clockwise rotation of the growing mandible, with a disproportionate increase in anterior lower vertical face height and decreased posterior facial height.

The present field of research can not be directly evaluated in an evidence based manner. The present study soley interests in the phylosophy of examination and diagnosis of children regarding dentofacial orthopaedics. Regarding treatment of dentofacial pathologies, different ecoles, associations may interfere different ways of treatment protocols. American Academy of Pediatric Dentistry presents guidelines regarding developing dentition and oral habits while dentofacial orthopaedics in children is underlined [26]. European Academy of Paediatric Dentistry recognizes the importance 

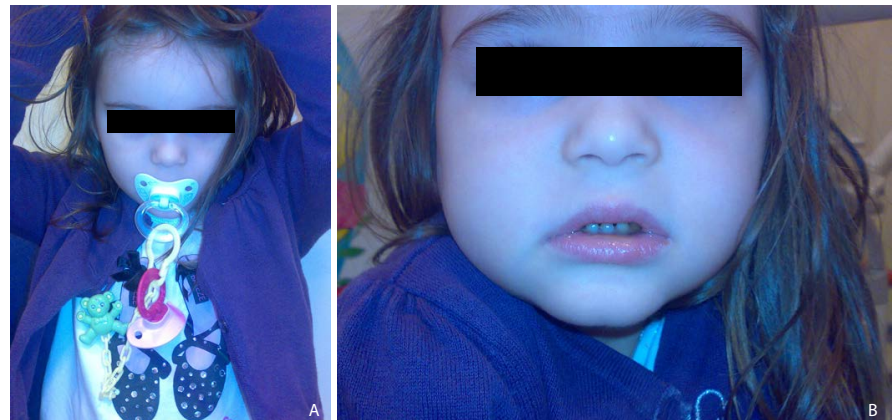

Figure 5A,B. A preschooler with fashionable dummies. Note also mouth breathing

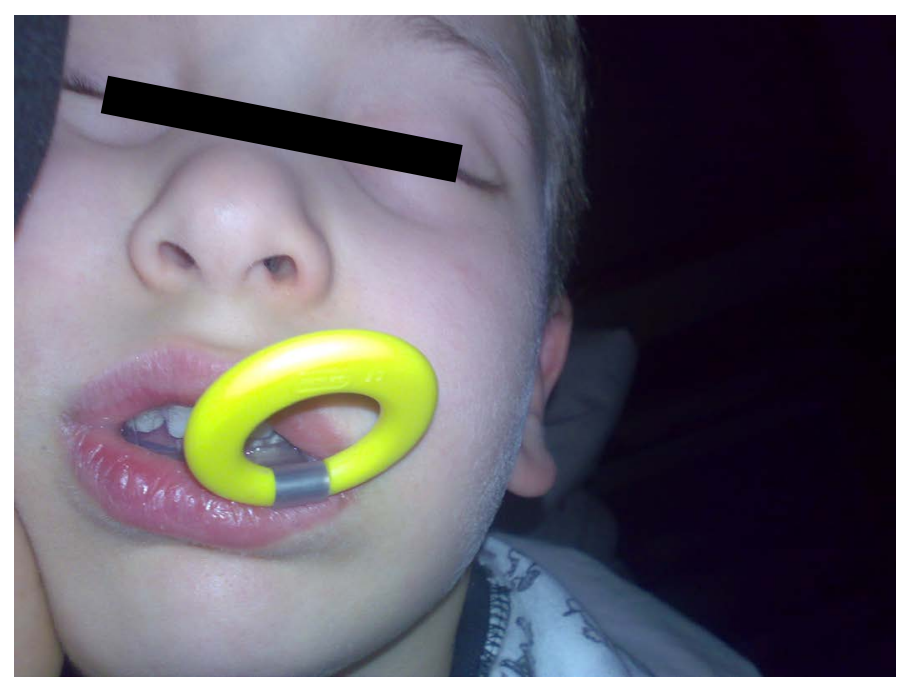

Figure 6. 5 yrs old boy wearing a trainer. Note at midnight he can not control his orbicularis oris mucles, trainer has shifted right and even teeth are seen

of subject with publishing many papers however there are currently no guidelines. Cochrane data base finds weak evidence of correction of dental malocclusions with pre-orthodontic appliances while notes the importance of randomised controlled trials to elucidate the interventions. [27]. Furthermore, there is also no sufficient evidence to state that oral appliances or functional orthopaedic appliances are effective in the treatment of OSAS in children. It is also noted that oral appliances or functional orthopaedic appliances may be helpful in the treatment of children with craniofacial anomalies.

In conclusion, while examing a child patient, the practioner should interfere with how the child's face looks, evaluate the proportions of the face, further check if there are any malocclusions, receive a good anamnesis of nasal and oral habits. It is also the practioner's main goal to guide the child patient to a related consultation with the team mates of otolaryngologists, pediatricians, pediatric dentists, orthodontists, aesthetic surgeons and speech therapists.

\section{References}

1. Thilander B, Lennartsson B (2002) A study of children with unilateral posterior crossbite, treated and untreated, in the deciduous dentitionocclusal and skeletal characteristics of significance in predicting the long-term outcome. $J$ Orofacial Orthoped 63: 371-383. [Crossref]

2. Melsen B, Stensgaard K, Pedersen J (1979) Sucking habits and their influence on swallowing pattern and prevalence of malocclusion. Eur J Orthod 1: 271-280.

3. Ovsenik M, Farcnik FM, Korpar M, Verdenik I (2007) Follow-up study of functional and morphological malocclusion trait changes from 3 to 12 years of age. Eur J Orthod 29: 523-529. [Crossref]
4. Proffit WR, Fields HW Jr, Sarver DM (2007) The etiology of orthodontic problems. In. Eds. Contemporary Orthodontics. 4th ed. Mosby Elsevier, St Louis.

5. Tourne LPM, Schweiger J (1996) Immediate postural responses to total nasal obstruction. Am J Orthod Dentofac Orthop 1996: 606-611.

6. Harari D, Redlich M, Miri S, Hamud T, Gross M (2010) The effect of mouth breathing versus nasal breathing on dentofacial and craniofacial development in orthodontic patients. Laryngos 120: 2089-2093. [Crossref]

7. Cazzolla AP, Lacarbonara V, Pellegrino B, Testa NF, Fidanza F, et al. (2010) Sleepdisordered breathing in a sample of 495 children in southern Italy. Eur J Paediatr Dent 11: 189-192. [Crossref]

8. Farcnik F, Rudel D (1995) The breathing detector - a new device in functional diagnosis of malocclusion. Zobozdravstveni Vestnik 50: 244-247.

9. Hafström M, Lundquist C, Lindecrantz K, Larsson K, Kjellmer I (1997) Recording non-nutritive sucking in the neonate. Description of an automatized system for analysis. Acta Paediatr 86: 82-90.

10. Larsson E, Bishara S (2003) The influence of oral habits on the developing dentition and their treatment. Skaraborg Institute 2nd ed. Skaraborg, Sweden.

11. Wolff PH (1968) The serial organization of sucking in the young infant. Pediatrics 42 943-956. [Crossref]

12. Larsson E (2003) The Influence of Oral Habits on the DevelopingDentition and Their Treatment: Clinical and Historical Perspectives. 2nd ed. Edited by S. Bishara. [n.p.] Sweden: CELA Grafiska.

13. Çaglar E, Larsson E, Andersson EM, Hauge M, Ogaard B, et al. (2005) Feeding, artificial sucking habits and malocclusions in 3 years old girls in different regions of the world. J Dent Child 72: 25-30. [Crossref]

14. Kargul B, Caglar E, Tanboga I (2003) Feeding practices and sucking habits in Istanbul children: a clinical study of prevalance and effects on dentition. J OHDMBSC 1: 20-25.

15. Nierberg LG (1960) An electromiographic and cephalometric investigation of the orofacial muscular complex. Am J Orthod 46: 627-628.

16. Isley CL Jr, Basmajian JV (1973) Electromyography of the human cheeks and lips. Anat Rec 176: 143-147. [Crossref]

17. Lindner A, Hellsing E (1991) Cheek and lip pressure against maxillary dental arch during dummy sucking. Eur J Orthod 13: 362-366. [Crossref]

18. Tosello DO, Vitti M, Berzin F (1998) EMG activity of the orbicularis oris and mentalis muscles in children with malocclusion, incompetent lips and atypical swallowing - Part I. J Oral Rehabilit 25: 838-846. [Crossref]

19. Ahlgren J (1995) EMG studies of lip and cheek activity in sucking habits. Swed Dent $J$ 19: 95-101. [Crossref]

20. Tonkin SL, Lui D, McIntosh CG, Rowley S, Knight DB, et al. (2007) Effect of pacifier use on mandibular position in preterm infants. Acta Paediatr 96: 1433-1436. [Crossref]

21. Meach C (1962) NUK Sauger Exerciser. Mich St Dent J 44: 340.

22. Rutrick RE (1974) Crossbite correction with a therapeutic pacifier. ASDC J Dent Child 41: 442-444. [Crossref]

23. Zimmer S1, Barthel CR, Ljubicic R, Bizhang M, Raab WH (2011) Efficacy of a novel pacifier in the prevention of anterior open bite. Pediatr Dent 33: 52-55. [Crossref]

24. Caglar E, Kuscu OO, Cildir SK, Kuvvetli SS, Sandalli N (2008) A probiotic lozenge administered medical device and its effect on salivary mutans streptococci and lactobacilli. Int J Paediatr Dent 18: 35-39. [Crossref]

25. American Academy of Pediatric Dentistry (2009) Guideline on Management of the Developing Dentition and Occlusion in Pediatric Dentistry.

26. Lentini-Oliveira DA, Carvalho FR, Ye Q, Luo J, Saconato H, et al. (2007) Orthodontic and orthopaedic treatment for anterior open bite in children. Cochrane Database Syst Rev 18: CD005515. [Crossref]

27. Carvalho FR, Lentini-Oliveira DA, Machado MAC, Saconato H, Prado LBF, et al. (2007) Oral appliances and functional orthopaedic appliances for obstructive sleep apnoea in children. Cochrane Database Syst Rev 18: CD005520.

Copyright: (C2018 Çaglar E. This is an open-access article distributed under the terms of the Creative Commons Attribution License, which permits unrestricted use, distribution, and reproduction in any medium, provided the original author and source are credited. 